\title{
Factors influencing the longevity and replacement frequency of Provox voice prostheses
}

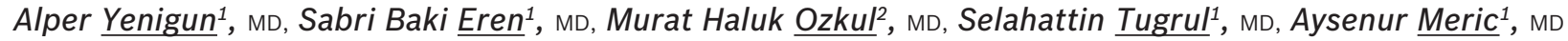

\begin{abstract}
INTRODUCTION This study aimed to assess the factors that influence the longevity and replacement frequency of Provox voice prostheses following their placement.

METHODS The medical records of 27 patients who received Provox voice prostheses after total laryngectomy and attended follow-up regularly between 1998 and 2012 were retrospectively reviewed. The success rate of the Provox voice prostheses (i.e. whether speech was achieved), quality of speech achieved, number and type of complications encountered, frequency of prostheses replacement and reasons for prostheses replacements were evaluated.

RESULTS All 27 patients were men and their mean age was 63.0 (range 43-78) years. The mean follow-up period was 60.3 (range 1-168) months. Fluent and understandable speech was achieved in $85.0 \%$ of the patients. The mean duration before prosthesis replacement had to be performed was 17.1 (range 1-36) months. The most frequent complication was fluid leakage through the prosthesis. There was a strong positive correlation of $77.1 \%$ between the longevity of prostheses and postoperative follow-up duration $(r=0.771 ; p<0.01)$.

CONCLUSION The voice prosthesis is a tool that can be delivered in a practical fashion and replaced easily with no serious complications. It is a means by which speech can be restored, with a high success rate, after total laryngectomy. In the present study, we found that postoperative follow-up duration was the most important factor influencing the longevity of the Provox voice prosthesis.
\end{abstract}

Keywords: Provox, total laryngectomy, tracheoesophageal fistula, voice prosthesis, voice rehabilitation

\section{INTRODUCTION}

As the voice is an important tool for communication, the loss of this function following total laryngectomy significantly affects the life and social activity of patients. Voice rehabilitation following total laryngectomy was first introduced by Guttman in 1932.(1) Guttman's shunt techniques via surgical tracheoesophageal fistula were used and further developed until the creation of a voice prosthesis by Singer and Blom. ${ }^{(1-3)}$ Methods such as oesophageal speech, the tracheoesophageal shunt, the electrolarynx and the voice prosthesis have been used for voice rehabilitation following total laryngectomy. However, the use of the voice prosthesis for voice restoration has been shown to be vastly superior to other methods. ${ }^{(4)}$ It has been reported that the voice prosthesis can result in speech that is more similar to laryngeal speech, giving the patient a longer lasting, better quality and more understandable voice. ${ }^{(5)}$ In this study, we aimed to identify the factors that influence the longevity and replacement frequency of voice prostheses.

\section{METHODS}

The present study was approved by the Ethics Committee for Clinical Research at Bezmialem Vakif University, Istanbul, Turkey. Patients who underwent total laryngectomy, received a Provox voice prosthesis (after the creation of a tracheoesophageal fistula) for voice restoration and were followed up between 1998 and 2012 were eligible for inclusion in the present study. Patients who received total laryngectomy and voice prostheses at external centres, had a follow-up period of less than three months and did not attend follow-up regularly were excluded.
During total laryngectomy, primary voice restoration was performed through the creation of a tracheoesophageal fistula, with the insertion of a 14 French ( $\mathrm{Fr}$ ) catheter for fistula epithelisation and feeding. Secondary voice restoration was performed under general anaesthesia using the endoscopic method: a fistula was created in the midline of the tracheoesophageal wall nearly $0.5 \mathrm{~cm}$ below the stoma during the second postoperative month or later. Prosthesis placement was scheduled to occur ten days after fistula epithelialisation was complete and after the patients achieved swallowing in the primary setting. The size of the prosthesis used was determined using a sizing apparatus and ranged between $6 \mathrm{~mm}$ and $10 \mathrm{~mm}$. No myotomy or pharyngeal plexus neurectomy procedures were performed during the surgeries. All previously laryngectomised patients underwent insufflation tests before the secondary tracheoesophageal puncture procedure.

The voice prostheses were replaced only if complications were observed and/or the patients requested a replacement during the control visits. None of the patients in the present study received preoperative radiotherapy. However, radiotherapy was performed postoperatively for some patients according to the advice of the oncology department. Patients who received postoperative primary voice restoration were encouraged to speak ten days after the procedure, while those who received secondary voice restoration were encouraged to speak the day the procedure was performed. Speech training was administered; the patients were also brought together for group therapy. Patients' maximum phonation duration and count points in one breath were checked

${ }^{1}$ Department of Otorhinolaryngology, Bezmialem Vakif University, ${ }^{2}$ Otorhinolaryngology Clinic, Haseki Education and Research Hospital, Istanbul, Turkey Correspondence: Dr Alper Yenigun, Instructor, Bezmialem Vakif University, Faculty of Medicine, Department of Otorhinolaryngology, Adnan Menderes Bulvarı Vatan Caddesi 34093 Fatih/İstanbul, Turkey. alperyenigun@gmail.com 
during the control visits in the first month following the placement of the Provox voice prosthesis.

During the study period, all the surgeons used the same technique for performing tracheoesophageal puncture (TEP). Patients attended monthly follow-up sessions for a duration of one year after the operation, after which the follow-up sessions were conducted quarterly for a year. Thereafter, follow-up was only done upon patient presentation at the centre. The presence of infection, discharge and granulation, as well as the function of prostheses, were evaluated during the patients' control visits. Indications for prosthesis replacement were divided into two categories: indications related to the (a) prostheses; and (b) fistula. Indications related to the prostheses included fluid leakage due to valve failure and increased air flow pressure while speaking due to prosthesis occlusion, while indications related to the fistula included fluid leakage around and through the prosthesis, use of inappropriate prostheses (e.g. inappropriate size/diameter), fistula infection, development of granulation and spontaneous prosthesis displacement/loss. If the fluid leakage originated from inside the prosthesis due to valve failure, the prosthesis would be replaced. If the fluid leakage was observed at the perimeter of prosthesis, the fistula length was measured and a prosthesis that was too long would be replaced with one of appropriate size. In cases where the fluid leakage originated from a fistula that was too wide, attempts were made to shrink the fistula by suturing the peripheral mucosa of the fistula and tightening it around the inserted $14 \mathrm{Fr}$ catheter. The diameter of the fistula was then measured and a new prosthesis placed.

During the control visits, the longevity of the voice prosthesis, the patient's voice quality, phonation duration and complications that could develop with the use of the prostheses were assessed. The effect of several factors (i.e. the patient's age, the distance of the fistula from the stoma, stoma width, history of reflux, antifungal use and placement time of the prosthesis) on the longevity and replacement frequency of the Provox voice prostheses (due to fluid leakage) were investigated. Statistical analysis was performed using the Number Cruncher Statistical System 2007 and Power Analysis and Sample Size 2008 statistical software (NCSS LLC, Kaysville, UT, USA). Descriptive statistical methods (e.g. mean, standard deviation, median, frequency and ratio), as well as the Mann-Whitney $U$ test (for two-group comparisons of parameters that did not demonstrate a normal distribution during the comparison of quantitative data) were used to assess the data. To evaluate the inter-parameter relationships, Spearman's correlation analysis was used. A p-value $<0.05$ indicated statistical significance.

\section{RESULTS}

A total of 27 patients in our centre met the inclusion criteria. Their mean age was $63.0 \pm 8.9$ (range $43-78$ ) years. The mean postoperative follow-up duration was $60.3 \pm 66.4$ (range 1-168) months. The mean total duration of Provox prosthesis use was $47.8 \pm 54.0$ (range 1-160) months, while the mean duration of the use of one Provox prosthesis was $17.1 \pm 19.5$ (range 1-36) months. A total of 77 Provox voice prostheses were used for
Table I. General characteristics of the patients $(n=27)$.

\begin{tabular}{|c|c|}
\hline Characteristic & Mean \pm SD (range) \\
\hline Age (yr) & $63.0 \pm 8.9(43-78)$ \\
\hline $\begin{array}{l}\text { Duration of postoperative } \\
\text { follow-up (mth) }\end{array}$ & $60.3 \pm 66.4(1-168)$ \\
\hline Total duration of prosthesis use (mth) & $47.8 \pm 54.0(1-160)$ \\
\hline $\begin{array}{l}\text { Duration of the use of one } \\
\text { prosthesis (mth) }\end{array}$ & $17.1 \pm 19.5(1-36)$ \\
\hline Distance from fistula to stoma $(\mathrm{cm})$ & $0.9 \pm 0.4(0.5-2.5)$ \\
\hline Stoma width $(\mathrm{cm})$ & $1.6 \pm 0.3(1.0-2.5)$ \\
\hline Phonation duration (s) & $8.0 \pm 5.0(0-20)$ \\
\hline Number counted to in one breath & $18.3 \pm 11.0(0-36)$ \\
\hline History of reflux* & $11(40.7)$ \\
\hline Antifungal use* & $10(37.0)$ \\
\hline \multicolumn{2}{|l|}{ Purpose of prosthesis placement* } \\
\hline Primary voice restoration & $17(63.0)$ \\
\hline Secondary voice restoration & $10(37.0)$ \\
\hline \multicolumn{2}{|l|}{ Colonisation in the prosthesis* } \\
\hline \multicolumn{2}{|l|}{ Present } \\
\hline Candida albicans & $3(11.1)$ \\
\hline $\begin{array}{l}\text { Candida albicans and } \\
\text { Pseudomonas aeruginosa }\end{array}$ & $1(3.7)$ \\
\hline Absent & $23(85.2)$ \\
\hline \multicolumn{2}{|l|}{ Location of fluid leakage* } \\
\hline Around the prosthesis & $4(14.8)$ \\
\hline Through the prosthesis & $9(33.3)$ \\
\hline Not detected & $14(51.9)$ \\
\hline
\end{tabular}

*Data presented as no. (\%). SD: standard deviation

Table II. Assessment of the relationship between the general characteristics of the patients and the longevity of the prosthesis.

\begin{tabular}{lcc}
\hline Characteristic & $\mathbf{r}$ & p-value \\
\hline Age & 0.10 & 0.59 \\
Duration of postoperative follow-up & 0.77 & $0.001^{*}$ \\
Distance from fistula to stoma & -0.15 & 0.43 \\
Stoma width & -0.39 & $0.04^{*}$ \\
Phonation duration & 0.29 & 0.14 \\
Number counted to in one breath & 0.34 & 0.07 \\
\hline
\end{tabular}

*Statistically significant $(p<0.05)$. r: Spearman's correlation coefficient

voice restoration during the study period. Among the 27 patients, 17 received the prosthesis for primary voice restoration during total laryngectomy, while the remaining ten patients received the prosthesis for secondary voice restoration following total laryngectomy. Patient data, such as distance of the fistula from the stoma, stoma width, phonation duration, number to which the patient could count in one breath, history of reflux, antifungal use, purpose of prosthesis placement and presence of colonisation and/or fluid leakage in the prosthesis, is shown in Table I.

We did not find any statistically significant relationships between the longevity of the Provox prosthesis and the patient's age, the distance from the fistula to the stoma, the phonation duration and the number up to which the patient could count $(p>0.05)$ (Table II). There was also no statistically significant difference between the longevity of the Provox prosthesis and the 
purpose of prosthesis placement (i.e. primary or secondary voice restoration), the presence of reflux history, antifungal use and the presence of fluid leakage ( $p>0.05)$ (Table III). We did, however, find a strong positive correlation of $77.1 \%$ between the longevity of the prosthesis and postoperative follow-up duration ( $r=0.771$; p < 0.01) (Table II \& Fig. 1). A significant negative correlation of $38.7 \%$ was also identified between the longevity of the voice prosthesis and stoma width $(r=-0.387 ; p<0.05)$ (Fig. 2).

\section{DISCUSSION}

The success rates of Provox prostheses in speech rehabilitation following total laryngectomy range between $65.9 \%$ and $91.0 \%$ (Table IV). ${ }^{(6-18)}$ Since the average success rate of oesophageal speech is only $33 \%$, the use of voice prostheses is often the preferred method for speech rehabilitation. ${ }^{(19-21)}$ The success rate of the Provox prosthesis in achieving speech in the present study (i.e. $85.0 \%$ ) is consistent with the rates reported in the literature. In the present study, $15.0 \%$ of the prostheses used were removed due to various reasons (e.g. lack of compliance with rehabilitation, complications and socioeconomic necessities).

Based on our literature review, we found that the average longevity of the Provox prosthesis varies. The shortest duration of Provox prosthesis use (before replacement) was reported to be 3.6 months, while the longest was reported to be 10.3 months. ${ }^{(9,17)}$ Demir et al reported that the minimum and maximum duration of Provox prosthesis use (before replacement) was 1 month and 49 months, respectively; the mean duration was 24 months. ${ }^{(14)}$ The long duration of prosthesis use was attributed to the fact that patients were carefully selected, the patient-physician relationship was maintained via strict follow-ups and prosthesis care was conducted regularly. ${ }^{(14)}$ In the present study, the longevity of Provox voice prostheses ranged from 1 month to 36 months, while the mean longevity was 17.1 months (Table IV).

The incidence of complications caused by the tracheoesophageal fistula created in patients using voice prostheses ranges between $20 \%$ and $70 \%$. The main complications include mediastinitis, cervical cellulitis, deep neck abscess, oesophageal perforation, aspiration pneumonia and prosthesis aspiration. ${ }^{(20,21)}$ Complications such as fluid leakage around or through the prosthesis, development of granulation tissue, accidental swallowing of the prosthesis and tracheostomal stenosis are more frequently encountered. None of the aforementioned main complications were encountered in the present study. However, fluid leakage around the prosthesis was identified in $4(14.8 \%)$ patients, fluid leakage through the prosthesis was identified in 9 (33.3\%) patients and granulation tissue development was observed in $1(3.7 \%)$ patient; these complications resulted in the replacement of the prosthesis in these patients.

The mean duration before the prosthesis had to be replaced was 17.1 (range 1-36) months. The Provox voice prostheses were replaced a total of 50 times during the follow-up period (1998-2012) for 15 of the 27 patients. Among the 27 patients, 77 prostheses were used - two patients used eight replacement
Table III. Assessment of the relationship between the general characteristics of the patients and the longevity of the prosthesis.

\begin{tabular}{|c|c|c|}
\hline Characteristic & Median (range) & p-value* \\
\hline Purpose of prosthesis placement* & & 0.98 \\
\hline Primary voice restoration & $27.0(1-160)$ & \\
\hline Secondary voice restoration & $32.0(1-106)$ & \\
\hline History of reflux & & 0.60 \\
\hline Not present & $29.0(1-160)$ & \\
\hline Present & $24.0(1-96)$ & \\
\hline Fungal colonisation in the prosthesis & & 0.46 \\
\hline Not present & $27.0(1-160)$ & \\
\hline Present & $36.5(11-106)$ & \\
\hline Antifungal use & & 0.88 \\
\hline Not present & $30.0(1-106)$ & \\
\hline Present & $21.0(1-160)$ & \\
\hline Fluid leakage from the prosthesis & & 0.13 \\
\hline Not present & $14.0(1-106)$ & \\
\hline Present & $45.0(1-160)$ & \\
\hline
\end{tabular}

*Mann-Whitney U Test

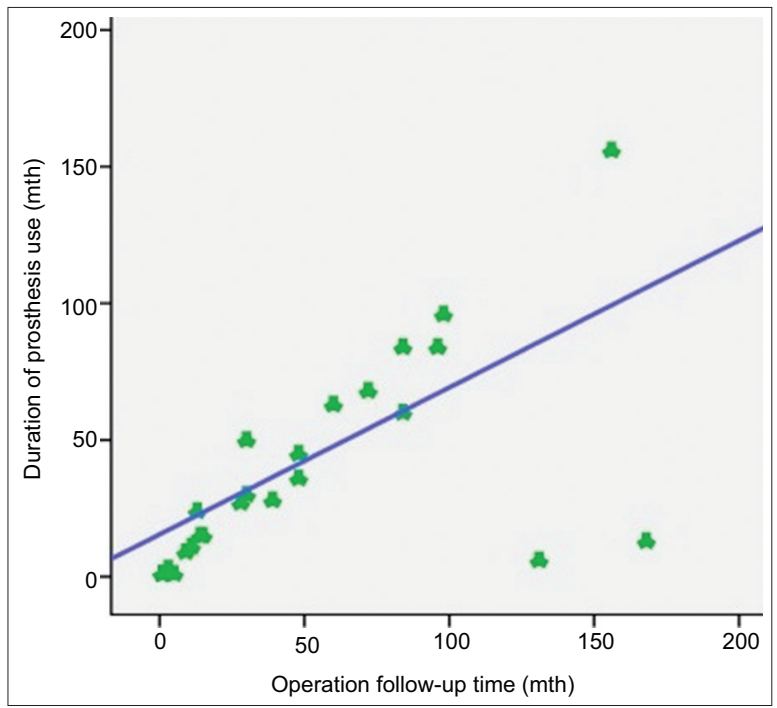

Fig. 1 Scatter graph shows the relationship between prosthesis longevity and postoperative follow-up duration.

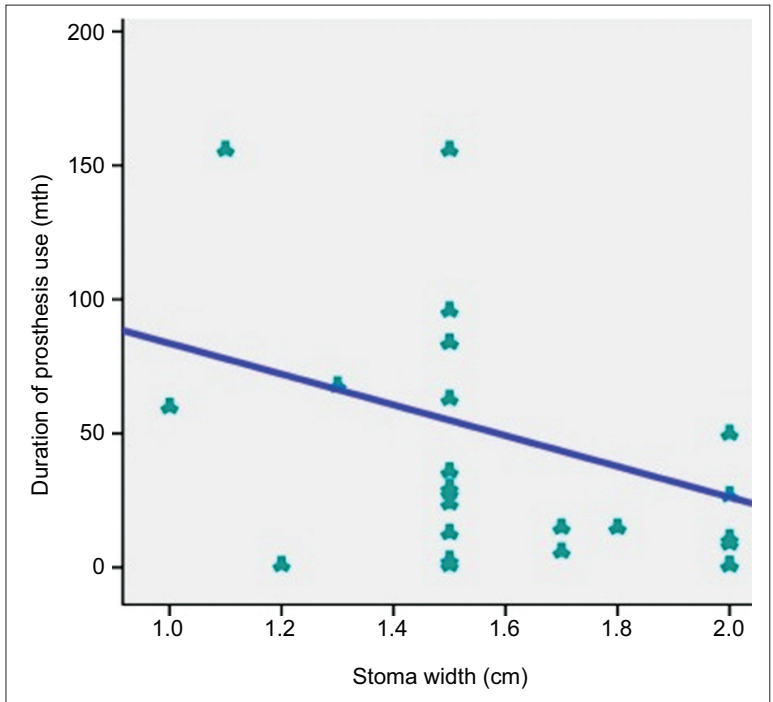

Fig. 2 Scatter graph shows the relationship between prosthesis longevity and stoma width. 
Table IV. Studies evaluating the use of the Provox prosthesis for voice rehabilitation.

\begin{tabular}{|c|c|c|c|c|c|c|c|}
\hline $\begin{array}{l}\text { Year of } \\
\text { publication }\end{array}$ & Study & $\begin{array}{l}\text { No. of } \\
\text { cases }\end{array}$ & $\begin{array}{l}\text { Type of } \\
\text { study }\end{array}$ & $\begin{array}{l}\text { Type of } \\
\text { TEP* }\end{array}$ & $\begin{array}{l}\text { Provox success } \\
\text { rate }(\%)\end{array}$ & $\begin{array}{c}\text { Average lifespan of } \\
\text { prosthesis (mth) }\end{array}$ & $\begin{array}{l}\text { RT } \\
\text { used }\end{array}$ \\
\hline 1991 & Hilgers and Schouwenburg(6) & 79 & Retrospective & 1 & 91.0 & 5.0 & No \\
\hline 1996 & de Carpentier et $\mathrm{al}^{(8)}$ & 39 & Retrospective & $1+2$ & - & 4.5 & Yes \\
\hline 1997 & Laccourreye et $\mathrm{al}^{(9)}$ & 37 & Retrospective & $1+2$ & 65.9 & 10.3 & Yes \\
\hline 1998 & Daniilidis et al(11) & 35 & Prospective & 1 & 82.8 & - & No \\
\hline 2000 & Ahmad et $\mathrm{al}^{(12)}$ & 83 & Retrospective & $1+2$ & 54.2 & - & No \\
\hline 2001 & Issing et $\mathrm{al}^{(13)}$ & 48 & Retrospective & 1 & 77.0 & - & Yes \\
\hline 2004 & Demir et $\mathrm{al}^{(14)}$ & 50 & Prospective & $1+2$ & 85.0 & 24.0 & Yes \\
\hline 2006 & Bień and Okła ${ }^{(15)}$ & 106 & Prospective & $1+2$ & 88.6 & 9.8 & Yes \\
\hline 2007 & Bilewicz et $a^{(16)}$ & 39 & Prospective & $1+2$ & 90.0 & 9.8 & Yes \\
\hline 2011 & Wierzchowska and Burduk(18) & 76 & Prospective & 2 & - & - & No \\
\hline 2014 & Present study & 27 & Retrospective & $1+2$ & 85.0 & 17.1 & Yes \\
\hline
\end{tabular}

*1: primary tracheoesophageal puncture; 2: secondary tracheoesophageal puncture. RT: radiotherapy; TEP: tracheoesophageal puncture

prostheses each (the highest number of replacements in a single patient), two patients used seven replacements each, two patients used six replacements each, one patient used five replacements, two patients used three replacements each, six patients used two replacements each and 12 patients used one replacement each. The number of prostheses replaced increased proportionally with the duration of follow-up. In the present study, the postoperative mean duration of follow-up for each prosthesis was 60.3 months.

Fluid leakage through the voice prosthesis can be attributed to several reasons. The most frequently observed reason is Candida albicans (C. albicans) colonisation in the valve system of the prosthesis. In the present study, $C$. albicans colonisation was observed in four of the $9(44.4 \%)$ patients who had fluid leakage through their prostheses (i.e. valve system failure). Hilgers and Balm reported that regular cleaning of the prostheses with antifungal solutions would increase the longevity of the prosthesis in patients suspected to have Candida infection. ${ }^{(22}$ In the present study, $C$. albicans colonisation was observed in $11.1 \%$ of the patients, while C. albicans and Pseudomonas aeruginosa colonisation was observed in $3.7 \%$ of the patients. Most of the patients $(85.2 \%)$ did not have prosthesis fungal colonisation (Table I). Fungal colonisation was found to have a statistically significant effect on the longevity of the Provox voice prosthesis in the present study $(p=0.04)$, but regular use of antifungal solutions did not have a statistically significant effect on the longevity of the Provox voice prosthesis $(p=0.88$ ) (Table III). Granulation tissue was observed in one patient in the present study. In that patient, the granulation tissue was locally excised and the prosthesis replaced.

The effect of radiotherapy (RT) before the implantation of a voice prosthesis via tracheoesophageal fistula has been discussed in the literature. A study conducted by Trudeau et al on 108 patients with voice prostheses found that RT did not affect the incidence of voice prosthesis complications. ${ }^{(23)}$ Trudeau et al reported that RT was not a negative prognostic factor for those who used voice prostheses and that RT did not increase the complication rate. In the present study, no significant correlation was identified between the complications encountered and RT exposure, which is in line with the findings reported in the literature. Demir et al demonstrated that age, $\mathrm{RT}$, prosthesis placement time, and duration between RT and prosthesis placement have no effect on the longevity of the Provox voice prosthesis. ${ }^{(14)}$ They observed that in their study, the longevity of the prosthesis was shortened by the complications seen during prosthesis use. ${ }^{(14)}$ In the present study, we did not find any statistically significant difference between the longevity of the prosthesis and the purpose of prosthesis placement, the presence of reflux history, antifungal use and the presence of fluid leakage. We believe that patient factors play an important role in the longevity of a prosthesis, especially the daily cleaning of the prosthesis in addition to oral and topical antifungal therapies. Shortcomings of patients (such as incompetency in prosthesis care, alcoholism and dementia) and hindrances in controls are important factors.

To conclude, the purpose of prosthesis placement, the presence of reflux history, antifungal use and the presence of fluid leakage did not affect the longevity of prostheses in the present study. We believe that frequent patient control visits, proper patient selection and regular prosthesis care can help prolong the longevity of Provox voice prostheses.

\section{REFERENCES}

1. Gutmann MR. Rehabilitation of the voice in laryngectomized patients. Arch Otolaryngol 1932; 15:478-88.

2. Singer MI, Blom ED. An endoscopic technique for restoration of voice after laryngectomy. Ann Otol Rhinol Laryngol 1980; 89:529-33.

3. Morrison MD, Ogrady M. Primary tracheo-esophageal puncture voice restoration with laryngectomy. J Otolaryngol 1986; 15:69-73.

4. St Guily JL, Angelard B, el-Bez M, et al. Postlaryngectomy voice restoration. A prospective study in 83 patients. Arch Otolaryngol Head Neck Surg $1992 ; 118: 252-5$

5. Williams SE, Watson JB. Speaking proficiency variations according to 
method of alaryngeal voicing. Laryngoscope 1987; 97:737-9.

6. Hilgers FJ, Schouwenburg PF. A new low-resistance, self-retaining prosthesis (Provox) for voice rehabilitation after total laryngectomy. Laryngoscope 1990; 100:1202-7.

7. Fukutake T, Yamashita T. Speech rehabilitation and complications of primary tracheoesophageal puncture. Acta Otolaryngol Suppl 1993; 500:117-20.

8. de Carpentier JP, Ryder WD, Saeed SR, Woolford TJ. Survival times of Provox valves. J Laryngol Otol 1996; 110:37-42.

9. Laccourreye O, Ménard M, Crevier-Buchman L, Couloigner V, Brasnu D. In situ lifetime, causes for replacement, and complications of the Provox voice prosthesis. Laryngoscope 1997; 107:527-30.

10. Aust MR, McCaffrey TV. Early speech results with the Provox prosthesis after laryngectomy. Arch Otolaryngol Head Neck Surg 1997; 123:966-8.

11. Daniilidis I, Nikolaou A, Markou C, Kotsani A. [Voice rehabilitation after total laryngectomy. Voice prostheses or esophageal replacement voice?] Laryngorhinootologie 1998; 77:89-92. German.

12. Ahmad I, Kumar BN, Radford K, O'Connell J, Batch AJ. Surgical voice restoration following ablative surgery for laryngeal and hypopharyngeal carcinoma. J Laryngol Otol 2000; 114:522-5.

13. Issing WJ, Fuchshuber S, Wehner M. Incidence of tracheo-oesophageal fistulas after primary voice rehabilitation with the Provox or the EskaHerrmann voice prosthesis. Eur Arch Otorhinolaryngol 2001; 258:240-2.

14. Demir D, Süoğlu Y, Emin H, Güven M, Kiyak E. [Factors that affect in situ lifetime of Provox voice prosthesis]. Kulak Burun Bogaz Ihtis Derg 2004; 13:126-31. Turkish.
15. Bień S, Okła S. [Analysis of complications after surgical voice and speech rehabilitation in laryngectomized patients. Problems related to implantation and change of voice prosthesis]. Otolaryngol Pol 2006; 60:129-34. Polish.

16. Bilewicz R, Burduk PK, Kopczyhiski A, Wierzchowska M. [The surgery voice rehabilitation after total laryngectomy with the Provox system]. Otolaryngol Pol 2007; 61:265-70. Polish.

17. Terada T, Saeki N, Toh K, et al. Voice rehabilitation with Provox 2 voice prosthesis following total laryngectomy for laryngeal and hypopharyngeal carcinoma. Auris Nasus Larynx 2007; 34:65-71.

18. Wierzchowska M, Burduk PK. [Early and late complications after implantation of the Provox 2 voice prosthesis in patients after total laryngectomy]. Otolaryngol Pol 2011; 65:184-7. Polish.

19. van Weissenbruch R, Albers FW. Voice rehabilitation after total laryngectomy. Acta Otorhinolaryngol Belg 1992; 46:221-46.

20. Wang RC, Bui T, Sauris E, et al. Long-term problems in patients with tracheoesophageal puncture. Arch Otolaryngol Head Neck Surg 1991; 117:1273-6.

21. Andrews JC, Mickel RA, Hanson DG, Monahan GP, Ward PH. Major complications following tracheoesophageal puncture for voice rehabilitation. Laryngoscope 1987; 97:562-7.

22. Hilgers FJ, Balm AJ. Long-term results of vocal rehabilitation after total laryngectomy with the low-resistance, indwelling Provox voice prosthesis system. Clin Otolaryngol Allied Sci 1993; 18:517-23.

23. Trudeau MD, Schuller DE, Hall DA. The effects of radiation on tracheoesophageal puncture. A retrospective study. Arch Otolaryngol Head Neck Surg 1989; 115:1116-7. 